\title{
Urbanization Transition Types and Zones in Tokyo and Kanagawa Prefectures
}

\author{
Loren SIEBERT \\ Department of Geography and Planning, University of Akron, Akron, OH 44325-5005, USA
}

\begin{abstract}
Spatial and temporal patterns of urbanization in Tokyo and Kanagawa were analyzed based on changes in administrative type from village to town to city to ward. Using a GIS, changes in these units between 1889 and 1995 were recorded from historical maps, half-decade censuses, and other sources. Many areas had sequential change (on a progression from village to town to city to ward), others had nonsequential change, skipping one or more steps, and some remain unchanged. There was an expanded core-city zone of nonsequential transition (from village or town directly to ward), an inland/coastal suburb zone of sequential transition (e.g., villages became a town, then towns became a suburban city), a foothills zone of nonsequential transition (e.g., villages and a town joined to become a city), and a mountaintowns zone of sequential transition (villages formed a town). These four zones form an alternating pattern of nonsequential, sequential, nonsequential, and sequential transition types. Areas adjacent to the core cities of Tokyo and Yokohama had nonsequential transitions, annexed as wards from villages or towns in the 1920s and 1930s. The next zone had gradual, sequential formation of mid-sized suburban cities, with most conversions to city occurring in the 1950s through 1970s. The third zone comprised satellite cities formed by nonsequential consolidation of villages and towns to form large mountain-edge cities, at various times during the century. The final zone had sequential change from mountain village to town. These urbanization transition zones reflect the differences in core, suburban, and satellite city growth patterns.
\end{abstract}

Key words: urbanization sequences, urbanization zones, Japan, Tokyo, Kanagawa, Yokohama, GIS-historical, villages, towns, cities, wards

\section{Introduction}

Japan's prefectures are subdivided into villages, towns, cities, and, for some cities, wards. In general, as settlements become more intensely developed, they progress from village status to town status, then city status, and perhaps eventually to ward status. Changes in these local administrative areas can thus serve as one measure of the urbanization process. Although there is a logical relationship, there may not always be a sequential progression.

In this study, I use a spatial history database constructed in a geographic information system (GIS) to document, visualize, and interpret the patterns of urbanization-as represented by sequence of obtaining higher administrative levels -in Japan's largest metropolitan area. By mapping and interpreting the sequences of such changes, I will characterize the broad zones of urbanization transition types that have spread outward from Tokyo city in Tokyo prefecture, and Yokohama city in Kanagawa prefecture.

Other researchers have looked at the patterns of urbanization in Tokyo from the perspective of density functions (Zheng 1991), the nature of building construction in different zones (Nakabayashi 1980), residential type in different zones (Ueno 1985), the role of planning and the concept of metropolitanism (Watanabe 1984), and preferences of different social geographic groups (Fluchter 1980). To my knowledge, no one has yet looked at the sequencing of village, town, city, and ward relationships. Though outwardly simple in concept, documenting and analyzing such patterns for all of the many historical administrative units that have made up the prefectures of Tokyo and 
Kanagawa is a major undertaking.

\section{Types of Local Administrative Units in Japan}

When looking at the nature of local administrative units in Japan, it is important to distinguish between toponymic territorial units and administrative territorial units. The term "toponymic territorial units" means the hierarchy of territorial areas and subareas whose names occur on maps, in postal addresses, in census tables, and in common usage. In contrast, the term "administrative territorial units" means the territorial subdivisions used for governmental purposes. Confusion of these two systems in Japan is easy because they use similar terms but have not always been organized in exactly the same way.

There are three tiers of toponymic territorial units in Japan (see left side of Table 1): prefectures at the top, counties and cities in the middle, and villages, towns, and wards (for some cities) at the bottom. As toponymic territorial units, villages and towns are subdivisions of counties, and wards are subdivisions of certain large cities.

In the toponymic system, every part of a prefecture belongs to either a county or a city, and every part of a county belongs to either a village or a town. That is, unlike many county systems in the United States, there is no "unincorporated" part of the county. As a result, the boundaries of villages, towns, and cities may not always closely correspond with the built-up area, since all agricultural, forest, and mountain areas are contained within a village, town, or even a city. This means that one must always be careful in viewing a map of Japanese town or city areas, since town or city boundaries may include much nonurbanized land.

Furthermore, once an area becomes a city, it is no longer part of the county. Thus, as cities emerge from a county, the county may become fragmented. This happens, for example, if a central band of a county becomes a city, leaving one portion of the county on one side of the city, and another on the other side.

The administrative territorial system and its history are somewhat different from the toponymic territorial system, with more historical variations in the structure of the system. Administrative units are geographic regions created for governmental purposes such as provision of public services and, in most cases, election of political representatives (e.g., mayors and legislative bodies). Prior to 1926 , this also was a three-tier system, with prefectures subdivided into counties and cities, counties subdivided into villages and towns, and the city of Tokyo subdivided into wards. However, in 1926 county governments were abolished, moving village and town governments up to the same tier as cities, directly under prefectures (see right side of Table 1). Consequently, thereafter there was no longer a one-to-one correspondence between the toponymic system and the administrative system.

Table 1. Japanese toponymic units versus administrative units

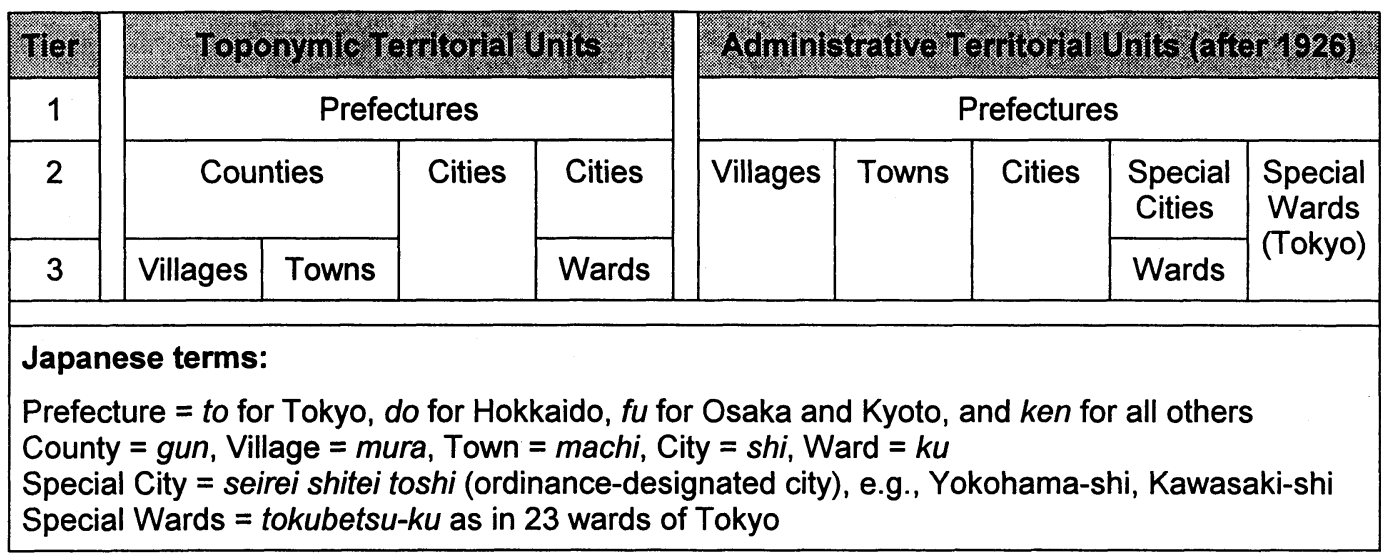


The case of cities with wards is even more complex. There are two types of cities with wards, and hence two types of wards-special wards (Tokyo only), and ordinary wards in special cities (such as in Yokohama and Kawasaki cities in Kanagawa prefecture). Tokyo city initially had 15 wards, in 1932 it expanded to 45 wards, and in 1947 it consolidated into 23 wards. After 1943, when Tokyo prefecture became Tokyo-to rather than Tokyo-fu, the city itself was no longer referred to as Tokyo city (Tokyo-shi); instead, the wards were collectively referred to as "the 23 wards" and individually as the special wards (tokubetsu-ku) within Tokyo Metropolitan Prefecture (Tokyo-to).

Each of Tokyo's special wards has its own elected mayor. Because there now is no such overall administrative unit as Tokyo "city," these special wards are "city-like" in nature, as reflected in the unofficial English names now being used by some wards, such as "Shinjuku City" and "Bunkyo City."

In contrast, ordinary wards exist in special cities that have been designated by ordinance (seirei shitei toshi). Wards in these cities exist for provision of government services, but do not have elected mayors; in that sense, they are only administrative in nature, in contrast to Tokyo's political/administrative wards. Yokohama city was first divided into wards in 1927, and Kawasaki city in 1972. Each went through several stages of expansion and reconfiguration of ward areas.

These four types of local administrative units in Japan-villages, towns, cities, and wardsrepresent different stages or levels of urbanization. The general increasing level of urbanization is indicated by the left-to-right sequence in Table 1: Villages are the least urbanized, towns are slightly more urbanized, cities are quite urbanized, and wards are very urbanized. By law, villages are areas with fewer than 30,000 inhabitants, towns with between 30,000 and 50,000 inhabitants, and cities with over 50,000 (Reischauer and Jansen 1995).

The specific population changes associated with changes in administrative levels in Tokyo and Kanagawa prefectures will be explored in a subsequent paper. For now, it is important to keep two points in mind: First, a change in administrative level without consolidation (e.g., when a single village becomes a town) normally is associated with an increase in population. Second, a change in level as part of a merger (e.g., when several villages are merged to form a single town) might not always be associated with an increase in the overall population-it might simply be a result of a consolidation to make provision of government services more efficient. Thus, changes in level as discussed in this paper are only one measure of urbanization.

There is, nevertheless, a natural thematic continuum in urbanization level from village to town to city to city with wards. To what extent has there also been a temporal and spatial continuum? From the temporal standpoint, have villages always become towns before they became cities, and what was the sequence of areas that became wards? From the spatial standpoint, did these changes occur in a uniform pattern outward from the core cities of the two prefectures, or were there distinct zones with different patterns of urbanization processes? My goal in this paper is to determine and evaluate these historical and geographic patterns associated with the conversion of administrative status (or level) of the villages, towns, cities, and wards in Tokyo and Kanagawa prefectures.

Although there is a difference, as explained earlier in this section, between toponymic and administrative territorial units, for simplicity hereafter, I will use the term administrative units to refer to both. Villages, towns, cities, and wards are all administrative and toponymic units.

\section{Data Sources, Data Input, and Database Design}

This analysis of historical changes in villages, towns, cities, and wards is expanded from the multifaceted "GIS spatial history of Tokyo" that I developed as my dissertation (Siebert 1997). In it, I used a geographic information system (GIS) to map and interpret various spatial patterns and changes in the greater Tokyo area: (1) shoreline and river changes, (2) administrative unit changes, (3) population changes, and 
(4) development of the rail network.

The administrative history component of the larger project analyzes the process of conversion from provinces to prefectures and various aspects of the history of local administrative units. In this paper, I explore one aspect of local administrative unit history-administrative status or level-in more detail for Tokyo and Kanagawa prefectures.

My GIS database on the spatial history of Tokyo records many different types of information about administrative units and their changes: locations, boundaries, names, administrative status or level (village, town, city, ward), and the nature of specific events such as mergers (units joining as equals), annexations (unequal joins), transfers (a portion of one area changes control), and splits (as happens when a city becomes a special city with wards). To record the physical location of these changes and the associated information, I used the following types of sources.

Census Data: Censuses taken every five years in the 1900s list the names and populations of cities, wards, counties, towns, and villages (Research Publications 1973, Bureau of Statistics 1950-1995). The early censuses (1903 to 1935) list administrative level but not specific events such as mergers or annexations, so I had to determine what happened to no-longer-listed areas by interpreting population changes and consulting maps. Wartime censuses list only some changes, mergers, and annexations. Later censuses (1950 onward) record level changes, mergers, and annexations and also include generalized boundary maps, making them the most useful. Only the more recent censuses (some wartime censuses and all since 1950) give the precise date (year, month, day) of administrative changes; for earlier times I initially used the census date as the date of the change (unless I found a particular event in another source).

Historical Maps and Atlases: Topographic maps show village, town, county, city, and ward names and boundaries. I initially used a set of once-per-decade historical topographic maps from the 1900s (Kokudo Chiri-in, 1900s-1990s) at a scale of $1: 50,000$ covering all of Tokyo city, most of its western suburbs, and part of northern Kanagawa prefecture, and another set at a scale of $1: 200,000$ covering the rest of Tokyo and Kanagawa prefectures. Thus, the precision of mapping was initially somewhat greater for most of Tokyo prefecture than for Kanagawa prefecture. These other areas are now being updated from a new set of $1: 50,000$ maps that include them as well, thus producing uniform coverage of the entire area of Tokyo and Kanagawa prefectures except two very small sections of the mountainous west.

The locations of some pre-1900s administrative units were identified from reproductions of some 1800s topographic maps (Nihon Chizu Center 1992, 1993, 1996). In some cases I also used other historical maps and atlases (Masai 1986, Yokohama 1981) to locate or cross-check information that could not be easily seen on the historical topographic maps due to occasional poor reproduction quality or when the time gap of the map series missed the administrative change I needed to locate. In other cases I had to use a subarea of a current city to determine the approximate location of no-longer-existing villages. This is sometimes possible because some current subdivisions (cho) within cities correspond to old independent villages or towns.

Place Name Dictionaries: The correct way to read Japanese place names written in Chinese characters (kanji) is not always clear, due to variety in the language itself and in local historical usage. Also, some place names were hard to read in the early censuses (from microfilm) and historical maps due to poor reproduction quality and/or small size of the characters. In some cases, place name dictionaries (Shogakukan 1996, Seikosha 1998, Takeuchi 1978, Yoshida 1937-1940) provided the correct reading of a name.

Administrative History Chronologies: Chronological tables in other sources proved useful for identifying certain changes and precise dates, especially transfers of areas from one prefecture to another (Yokohama 1981, Masai 1986, Ishizuka and Ishida 1988, TMG Planning 1989).

Annexation Charts: After the dissertation was complete, I located a book (Ota 1995) that records name changes (including correct readings), status changes, mergers, and annexations in chart form, and includes precise dates. I used 
this source to double-check all of the information I had previously derived separately from other sources.

As the first step of data input, the historical topographic maps were scanned into the computer for use as "backdrops" for tracing boundaries of administrative territorial units. I started by tracing the current prefecture boundaries, then the current village, town, county, city, and ward boundaries within each prefecture. I then stepped back one census period (five years) and, by consulting the applicable topographic map and census table, subdivided each area that had undergone a merger or annexation in that period.

Each area was coded in the accompanying GIS database to record its condition for each half decade: name, name change, level, level change, and type of event (merger, annexation, transfer, split). Related tables record the population for each geographic unit in existence at each half decade. In addition to these halfdecade records of conditions, the GIS database also records the exact date (year, month, day) of all administrative changes so smoother, finerdetail analyses can also be done.

By repeating this process backward in time, I produced a full record of geographic changes of administrative units and associated descriptive information in the GIS database. I worked backward for several reasons: First, the current maps have been more accurately surveyed and thus serve as better base maps. Second, current administrative units are generally larger, and their number smaller, than in previous decades, making their boundaries easier to locate and trace. Third, the reproduction quality of recent materials (both maps and censuses) was better than that of the older materials. Fourth, as a native of Tokyo who lived there in the second half of the $1900 \mathrm{~s}$, I found that my own personal knowledge allowed me to quickly locate many features on current maps, but the process naturally became more difficult in earlier decades.

Despite some difficulties with map and census reproduction quality and with unavailable data types in the earlier censuses, I have been able to locate almost all local administrative units and their major boundary changes since the late 1800 s. In a few cases I still lack a suitable source map to show the original boundaries of some villages that merged in the late 1800 s or early $1900 \mathrm{~s}$. For these areas, I have drawn a straight line to subdivide the now-larger area; because political boundaries in Japan are almost never straight lines, any such long straight line in my maps can be assumed to be for one of these approximate areas. In some cases I drew an approximate border based on the nature of the entity and, perhaps, a modern cho that still uses its name. In a few cases where the old historical map was particularly difficult to read, I assumed that a boundary followed a ridgeline or river. Thus, there are some areas of insufficient data and mapping precision. However, none of these is significant enough to impact the analysis of urbanization processes in this paper.

\section{Physical Context}

The physical geography of a region is one factor in the location and distribution of urbanization. Generalized landform regions of Tokyo and Kanagawa prefectures are mapped in Figure 1 to set this physical context.

Tokyo and Kanagawa are located in the southern portion of Japan's largest flatland area, the Kanto Plain. Both are coastal prefectures, with Tokyo bounded by Tokyo Bay on the east, and Kanagawa bounded by Tokyo Bay on the east and Sagami Bay on the south (separated by Miura Peninsula).

Similarly, both prefectures are bounded by portions of the Kanto Mountains on the west: Tokyo by the Okutama area of the Chichibu Mountains, and Kanagawa by the Tanzawa Mountains. Kanagawa is also bounded by the Hakone Mountains on the southwest. A foothills area can also be mapped for these mountain areas.

The Kanto Plain area of each prefecture is not completely flat. It consists of two parts: the area of low hills and valleys as well as deltalands in the eastern portion along Tokyo Bay, and several distinct areas of flatter land in the center of the prefectures. In Tokyo, these flatter areas are the Musashino upland plain, and in Kanagawa they are the Sagamino or Sagamihara upland plain and the flat lands 


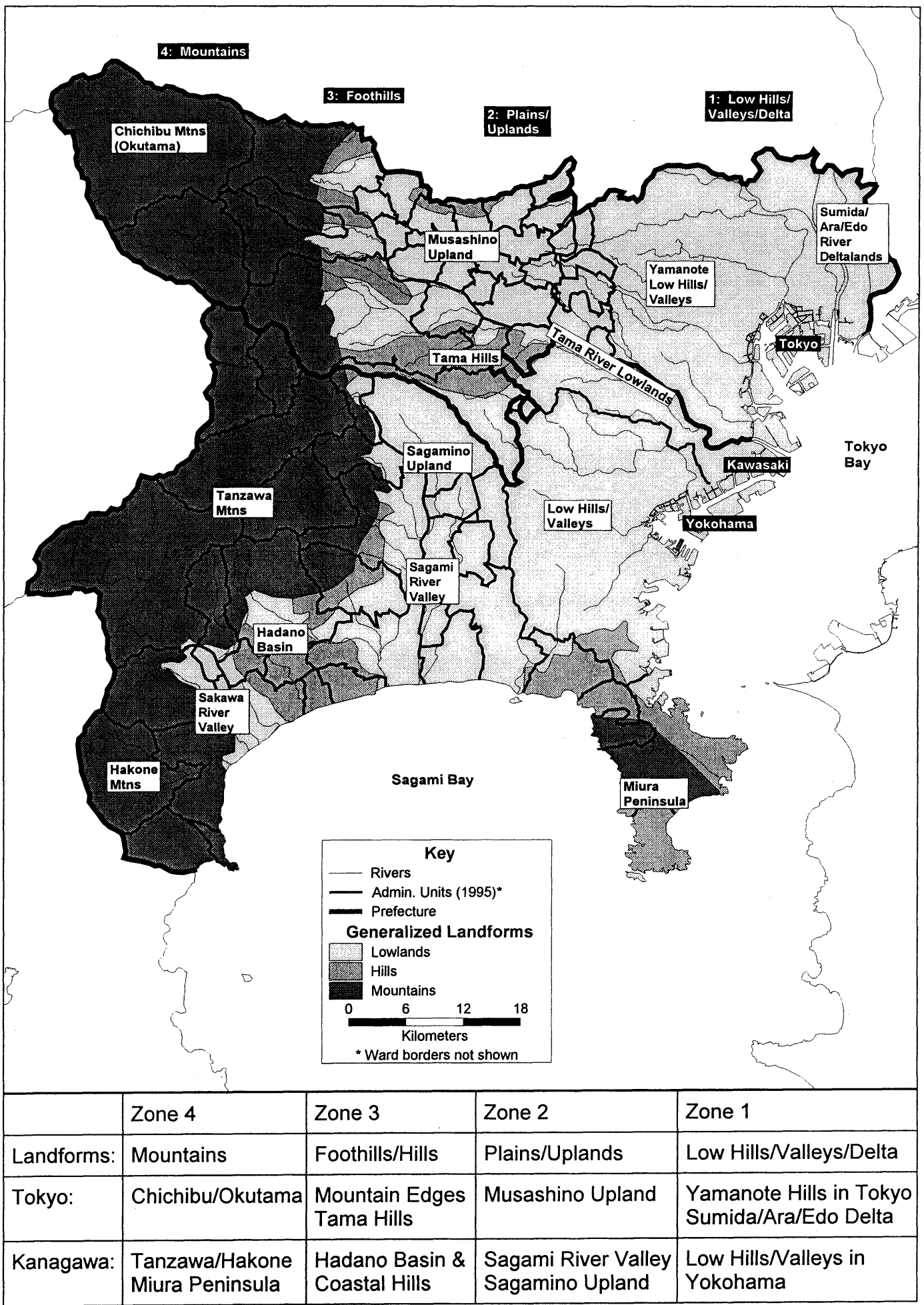

Figure 1. Landform regions in Tokyo and Kanagawa. 


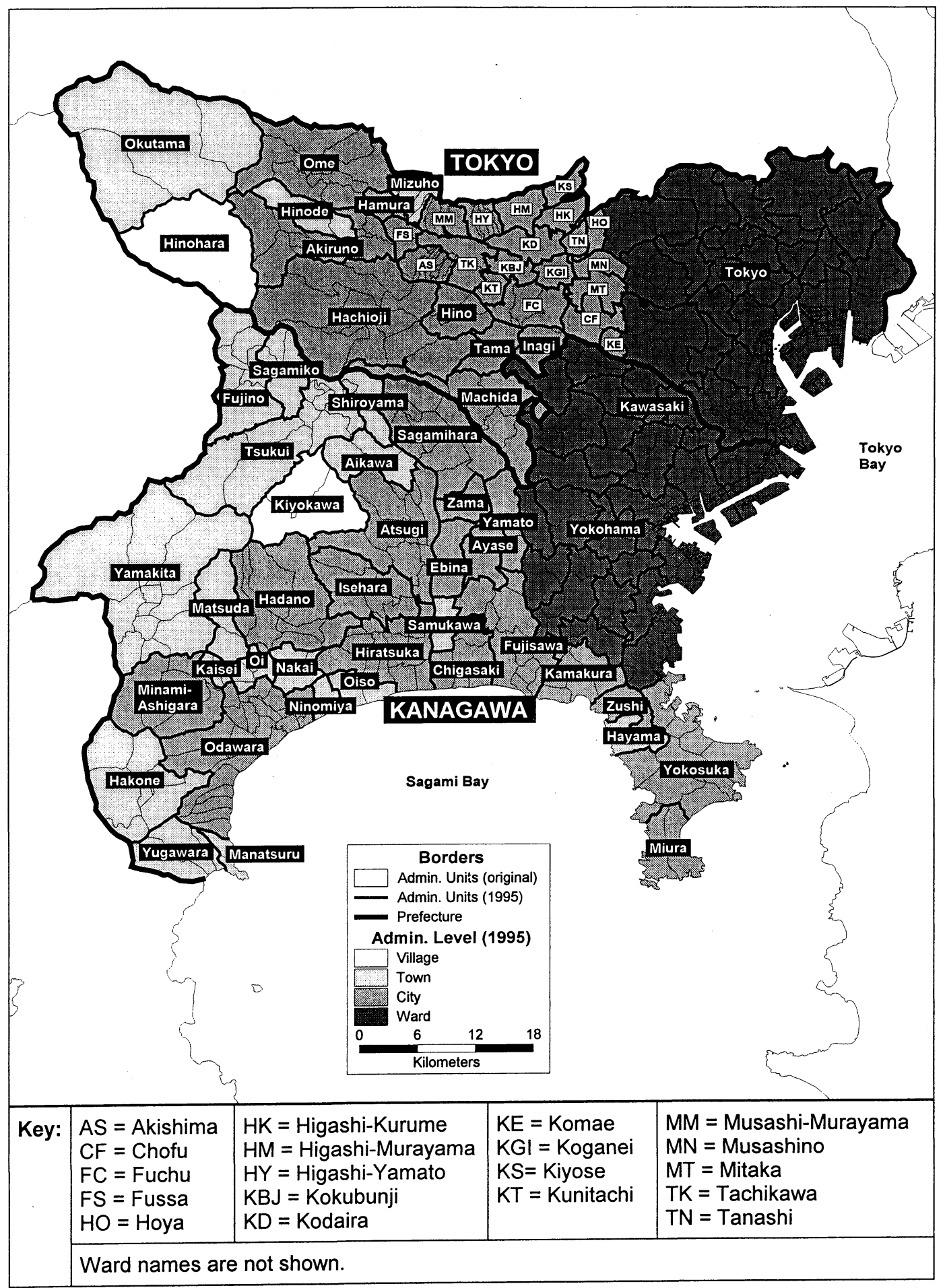

Figure 2. Administrative areas and levels in Tokyo and Kanagawa in 1995. 
along the Sagami River and the coast of Sagami Bay.

\section{Current Administrative Level and Decade Obtained}

Administrative areas and levels in Tokyo and Kanagawa prefectures as of 1995 are mapped in Figure 2. Thick lines are prefecture borders; medium lines are borders of current villages, towns, cities, and wards; and thin lines are borders of the original administrative units (as of 1889). These thin lines reveal the subareas that were annexed or merged to form the current administrative areas. Current (1995) village, town, and city names are shown.

Tokyo, Yokohama, and Kawasaki each have wards, though Tokyo's wards have a different status than the wards of Yokohama and Kawasaki. Most of the remaining areas of both prefectures are cities, and a few areas in each prefecture still are towns or villages. The nonmountainous areas of both prefectures are now almost all in cities or wards (compare with Figure 1).

The temporal processes of conversion from village to town to city (and/or ward) were documented and analyzed in the dissertation and will form the topic of a separate moredetailed paper. Here, I will simply present one aspect of the analysis - the decade in which the current administrative level was obtained (Figure 3) and describe the broad temporal patterns. Because this map deals only with changes in level, areas that merged but did not change levels are not shown as having changed (e.g., when villages merged to form a new village).

Dark gray depicts areas that have not changed level since the 1800s: the original wards of Tokyo, a mountain village in Tokyo, a large village in Kanagawa, and several small areas in Kanagawa that have always been towns.

Areas that reached their current level in the 1900 s or 1910 s are shown by line patterns. Yokosuka became a city in 1907, and Hachioji in 1917. Several small areas in Kanagawa became towns in the 1910s.

Medium grays depict areas that reached their current level in the 1920s and 1930s. Tokyo expanded slightly in 1920, and extensively in 1932, then slightly in 1936; Tokyo's new wards were created simultaneously with annexation. Yokohama became a city in the late 1800 s, annexed several towns and villages in 1901 and 1911 , and then annexed many areas in the 1920s and 1930s; wards were first formed in 1927. Kawasaki became a city in 1924 and expanded later that decade and in the 1930s; it was not divided into wards until 1972. Kanagawa has several other areas that obtained their current level in the 1920s and 1930s, including the original core areas of Kamakura and Hiratsuka cities.

The 1940s (light gray) had a significant number of areas obtain their current status, including Musashino and Tachikawa cities and an addition to Hachioji city in Tokyo prefecture, and Fujisawa, Chigasaki, and Odawara cities and additions to Yokosuka city in Kanagawa prefecture.

The 1950s saw a very large number of changes as a result of adoption in 1953 of the Special Act for the Promotion of Merger of Local Administrative Units (Ishizuka and Ishida 1988). Many areas in the middle part of Tokyo prefecture went from village to town (not revealed here), and some of those that were already towns became cities (Mitaka, Chofu, Fuchu, Koganei, Machida, Akishima, and Ome). In addition, Hachioji city grew considerably. In Kanagawa prefecture, Fujisawa, Chigasaki, Hiratsuka, and Odawara expanded, and Miura, Yamato, Sagamihara, Atsugi, Hadano, and Zushi cities were formed (Zushi town had earlier temporarily become a part of Yokosuka city). Thus, the middle portions of both prefectures were starting to fill in with cities. In the hillier and mountainous areas, many villages merged and were upgraded to town status during the 1950s.

The 1960s and 1970s were the decades during which almost all of the middle portions of Tokyo and Kanagawa prefectures were filled in with new cities (too many to name here). In addition, several new foothill cities were formed, including the original Akikawa city in western Tokyo prefecture and Isehara and Minami-Ashigara cities in western Kanagawa 


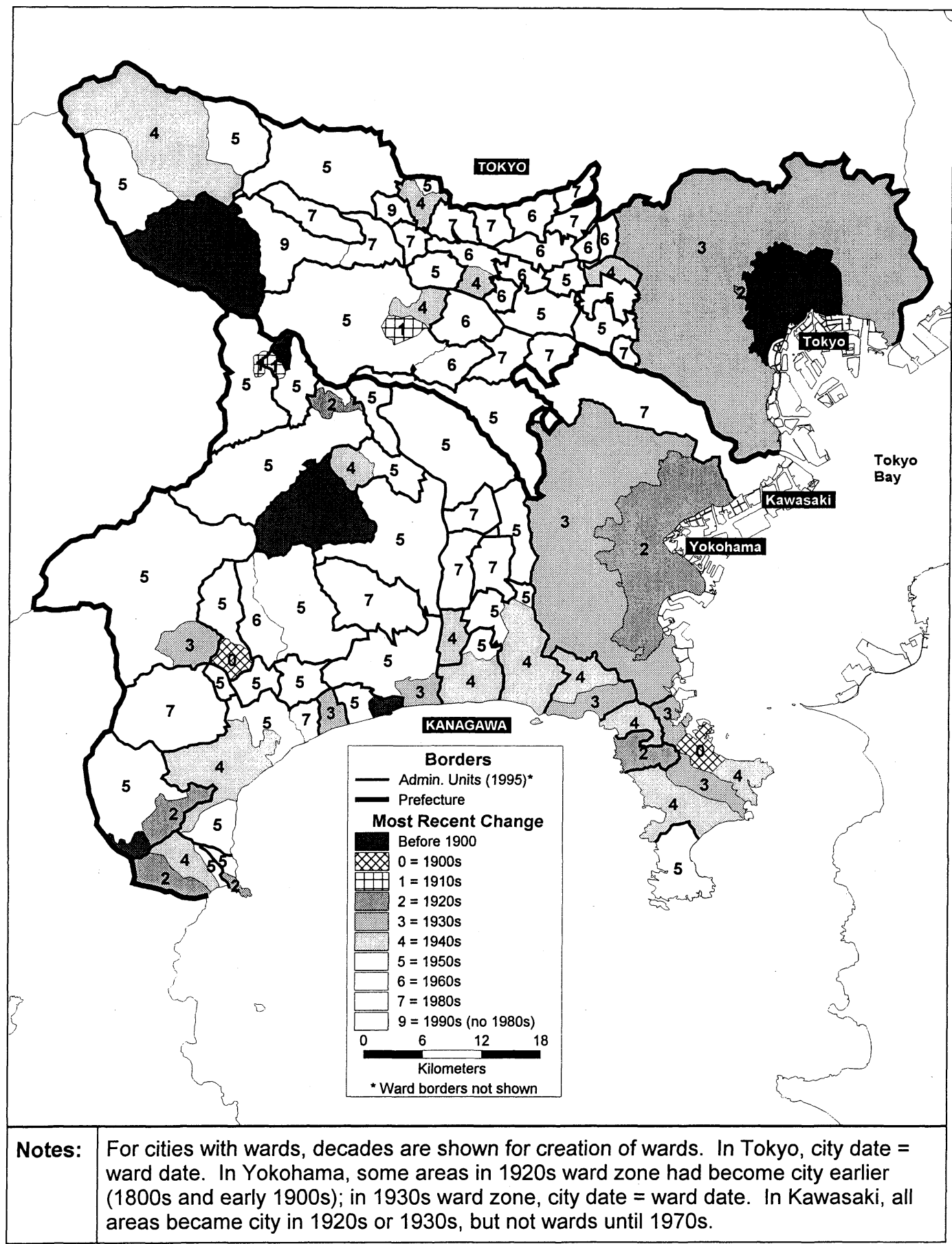

Figure 3. Decade current administrative level was obtained.

prefecture.

No level changes occurred in the 1980s, and only one in the 1990s (in 1995, Itsukaichi town merged with Akikawa city to become Akiruno city).

In summary, the temporal and spatial patterns of change in administrative level in Tokyo and Kanagawa prefectures are: First, the 
core cities of Tokyo and Yokohama were formed in the late 1800 s and then expanded significantly in the 1920s and 1930s. Second, major outlying cities were formed in the early decades of the century: Yokosuka in the 1900s, Hachioji in the 1910s, Kawasaki (an intervening city) in the 1920s, Kamakura and Hiratsuka in the 1930s, and Tachikawa, Musashino, Fujisawa, Chigasaki, and Odawara in the 1940s. Third, the 1950s through 1970s were decades of extensive conversion of towns to cities, especially in the uplands and plains in the central parts of the prefectures, but also in the foothill areas. In addition, those decades saw most villages converted to towns or merged into cities. Broadly speaking, the first half of the century can be characterized as core-city expansion and satellite-city formation, and the second half of the century as suburban-city infill.

\section{Urbanization Transitions: Sequences of Changes in Administrative Level}

Besides the decade in which a change in administrative level occurred (as described in the previous section), it is important to look at the sequence in which the changes occurred. Although there is an inherent logical continuum from village to town to city to city ward (as explained earlier), that does not mean all administrative units must follow that sequence. At the heart of the analysis in this paper are, therefore, these questions: Do all administrative units follow that logical continuum, or do some of them skip some of the steps, or even reverse some of the steps? An investigation of detailed conversion sequences, their geographic distribution, and their temporal patterns will provide the answers to these questions and reveal the nature of urban expansion-as measured by changes in administrative level-in Tokyo and Kanagawa prefectures.

To make this analysis possible, each historical administrative unit in my GIS spatial history database has been given a code indicating the sequence by which it changed its administrative level, using the number " 1 " for village level, " 2 " for town, " 3 " for city, and " 4 " for ward. Thus, a spatial unit with a "level history" coded as " 12 " went from village to town between 1889 and 1995 (and currently is a town), one coded "1234" went from village to town to city to ward, and one coded " 124 " went from village to town, then directly to ward. For simplicity in this analysis, I do not record duplicates at the same level (e.g., "village $>$ village $>$ town" is treated as "12" rather than "112").

When conducting and interpreting an analysis such as this, it is important to consider the temporal resolution of the data. When I first investigated these sequences as a prototype study within the dissertation, I was limited to dates with half-decade accuracy for some areas and eras; thus some changes could be hidden within a five-year period, and others were hidden within the year. Now, for this analysis, I have exact dates, enabling consideration of multiple events within a year, thereby conveying the true historical sequence of changes.

In the case of Tokyo city, the city was established in the late 1800 s with 15 original wards. When one town (Naito-Shinjuku) was annexed in 1920, it was annexed directly into an existing ward. When many towns and villages were annexed in 1932, they were simultaneously grouped into 20 new wards. Thus, no part of Tokyo city went through the ordinary-city level. In contrast, Yokohama's core area became a city in the late 1800s, expanded as an ordinary city in 1901 and 1911 , and then again in April of 1927. Later that year (October), the city was divided into five wards. When other areas were annexed by the city in the late 1920 s and the 1930s, they either entered existing wards or were grouped to form new wards. Thus, Yokohama has some areas that went through the ordinary-city level, and some that skipped it. Although some of them (those annexed in April 1927 and split into wards in October) were only in an ordinary city for five months, I chose to treat them as having gone through the stage because, in fact, they had, however short it was. There were a few similar cases of quite brief passage through town status on the way to becoming a city.

Because an administrative area may not follow the continuum in its logical step-by-step sequence or even in its natural order, I call these historical patterns "urbanization transitions" rather than "urbanization sequences." 
Table 2. Urbanization transition types in Tokyo and Kanagawa

\begin{tabular}{|c|c|c|c|c|c|c|c|}
\hline \multicolumn{3}{|c|}{ Change in Administrative Level } & \multicolumn{2}{|c|}{ Skipped } & \multicolumn{3}{|c|}{ Units in Prefecture } \\
\hline Code & Transition & Type & Types & Steps & Tokyo & Kanagawa & Total \\
\hline 1 & Village only & No change & & & 1 & 2 & 3 \\
\hline 12 & $V>T$ & Sequential & & & 10 & 65 & 75 \\
\hline 123 & $V>T>C$ & Sequential & & & 62 & 51 & 113 \\
\hline 1234 & $\mathrm{~V}>\mathrm{T}>\mathrm{C}>\mathrm{W}$ & Sequential & & & 0 & 12 & 12 \\
\hline 124 & $V>T>W$ & Nonsequential & C & 1 & 68 & 2 & 70 \\
\hline 13 & $V>C$ & Nonsequential & $T$ & 1 & 20 & 49 & 69 \\
\hline 134 & $V>C>W$ & Nonsequential & $T$ & 1 & 0 & 28 & 28 \\
\hline 14 & $V>W$ & Nonsequential & $T>C$ & 2 & 27 & 23 & 50 \\
\hline 2 & Town only & No change & & & 0 & 2 & 2 \\
\hline 23 & $T>C$ & Sequential & & & 5 & 13 & 18 \\
\hline 234 & $\mathrm{~T}>\mathrm{C}>\mathrm{W}$ & Sequential & & & 0 & 3 & 3 \\
\hline 24 & $T>W$ & Nonsequential & $C$ & 1 & 10 & 1 & 11 \\
\hline 3 & City only & No change & & & 0 & 0 & 0 \\
\hline 34 & $C>W$ & Sequential & & & 0 & 3 & 3 \\
\hline 4 & Ward only & No change & & & 15 & 0 & 15 \\
\hline \multirow{3}{*}{\multicolumn{2}{|c|}{ Subtotals }} & No change & & & 16 & 4 & 20 \\
\hline & & Sequential & & & 77 & 147 & 224 \\
\hline & & Nonsequential & & & 125 & 103 & 228 \\
\hline \multicolumn{2}{|c|}{ TOTALS } & All & & & 218 & 254 & 472 \\
\hline \multicolumn{8}{|c|}{ Reversals } \\
\hline 12123 & $V>T>V>T>C$ & \multicolumn{6}{|c|}{$\begin{array}{l}\text { Shibuya } V>\text { Shibuya } T>\text { part }>\text { Fujisawa } C \\
\text { Shibuya } V>\text { Shibuya } T>\text { part }>\text { Shibuya } V>\text { Yamato } T>\text { Yamato } C\end{array}$} \\
\hline 12323 & $\mathrm{~V}>\mathrm{T}>\mathrm{C}>\mathrm{T}>\mathrm{C}$ & \multicolumn{6}{|c|}{ Takoe $\mathrm{V}>$ Zushi $\mathrm{V}>$ Zushi $\mathrm{T}>$ Yokosuka $\mathrm{C}<$ Zushi $\mathrm{T}>$ Zushi $\mathrm{C}$} \\
\hline 214 & $T>V>W$ & \multicolumn{6}{|c|}{ Kamakura $T>$ part $>$ Mutsuranosho $V>$ Kanazawa $W$} \\
\hline
\end{tabular}

The historical urbanization transitions for administrative areas in Tokyo and Kanagawa prefectures are listed in Table 2 and mapped in Figure 4. The main portion of the table lists all possible normal-direction transitions (i.e., those that progress upward in level). The bottom part lists the three cases that had a reversal; there could theoretically be many more possi- ble transition histories than the three that actually occurred here.

The transitions have been categorized into three types: no change, sequential change, and nonsequential change. In the case of nonsequential transitions, I indicate which levels were skipped and the number of levels skipped. The only normal-direction transition that skips 


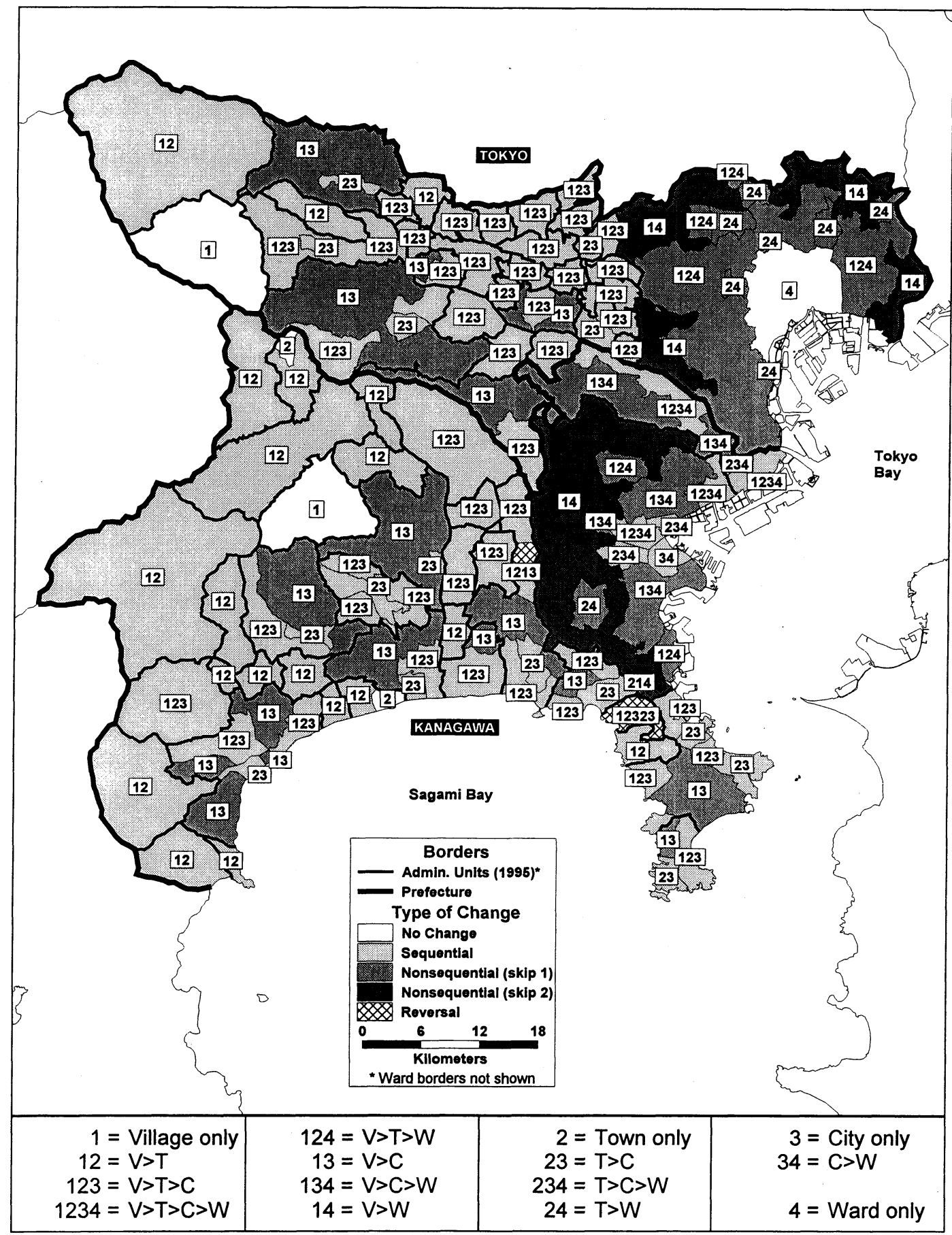

Figure 4. Urbanization transition sequences in Tokyo and Kanagawa.

two levels is when a village goes directly to ward level (marked 14 or V $>$ W). Strictly speaking, an administrative area that starts out as a town, city, or ward could be said to have skipped the preceding levels, but I do not treat it that way since doing so would involve the pre-1889 history of the area.

The table and map do not include the transi- 
tion histories of landfill areas in Tokyo Bay. Although that information is recorded in the underlying database, including the results here would complicate the analysis and maps without adding essential information. The initial administrative level of these landfill areas would be mapped based on the time they became part of the adjacent mainland area, but that mainland area may have started at a lower level.

A detailed analysis and interpretation of the transition types and their distribution will be given in the next section. Here I will just describe some of the actual locations and quantitative patterns.

Only a few areas are marked "no change" (village only, town only, city only, or ward only). Hinohara in Tokyo prefecture has always been a village (in fact, it has undergone no mergers or name changes and thus is the only completely unchanged area), and the area that is now Kiyokawa village in Kanagawa prefecture has always had village status (first as two villages). Tokyo has no areas that have only been towns; Kanagawa has two (Oiso and the former Ohara). Neither prefecture has an area that has always been only a city. Finally, only Tokyo has ward-only areas (the 15 initial wards were, in fact, wards even before 1889).

There are many types of areas with sequential transition histories (shown in light gray). Of the six types, Tokyo prefecture has three (types 12, 123, and 23) and Kanagawa prefecture has all six (those three types, plus types 1234,234 , and 34 ). Overall, the "village $>$ town $>$ city" transition type has the most occurrences (113 units), followed by the "village $>$ town" transition type (75 units). These patterns reflect the fact that most areas started out as villages.

There are also many types of areas with nonsequential transition histories (shown in medium gray for those that skipped one level, and dark gray for the one type that skipped two levels). Tokyo prefecture has four out of five (types 124, 13, 14, and 24), and Kanagawa prefecture has all five (those four types, plus 134). Overall, the most common types are "village $>$ town $>$ ward" (70 units) and "village $>$ city" (69 units).
The three cases of reversal (bottom of Table 2, and line pattern in Figure 4) are complicated anomalies: (1) Shibuya town was split so part of it could join Fujisawa city, while the other part returned to village status before later being annexed by Yamato town, which later became a city, (2) Zushi town was temporarily merged into Yokosuka city during World War II, and (3) a portion of Kamakura town was transferred to Mutsuranosho village, which later joined Kanazawa ward of Yokohama.

Looking at the subtotals for the three main types in Table 2, we can see that both Tokyo and Kanagawa prefectures had some areas of no change and many areas of sequential or nonsequential transitions. Tokyo prefecture had significantly more units with nonsequential transitions than sequential transitions (125 vs. 75 ), while Kanagawa prefecture had more units with sequential transitions than nonsequential transitions (147 vs. 103). The spatial patterns of distribution of these three general urbanization transition types will be investigated next.

\section{Urbanization Transition Zones}

The map of urbanization transition types in Figure 4 shows the distribution of the different types by grayscale shading and as sequence labels. Figure 5 shows the same underlying data, but without the sequence labels and with both nonsequential types shown in the same shade of gray. Interpretive symbols and labels have also been added (compare with Figure 1 on landforms) to correspond with the following description and interpretation.

Figure 5 reveals that there are several distinct (but not always pure) geographic zones of urbanization transition types in Tokyo and Kanagawa prefectures.

Zone 0: Each prefecture has a large eastern city (Tokyo and Yokohama) with a core area that experienced either no change in administrative level (Tokyo's initial 15 wards) or sequential change (Yokohama's initial city core and some towns-including the town of Kanagawa-it annexed on the north). In the case of Tokyo, this is the old city of Edo, the shogun's capital in the Tokugawa era. In the case of Yokohama, this is the fishing village and 


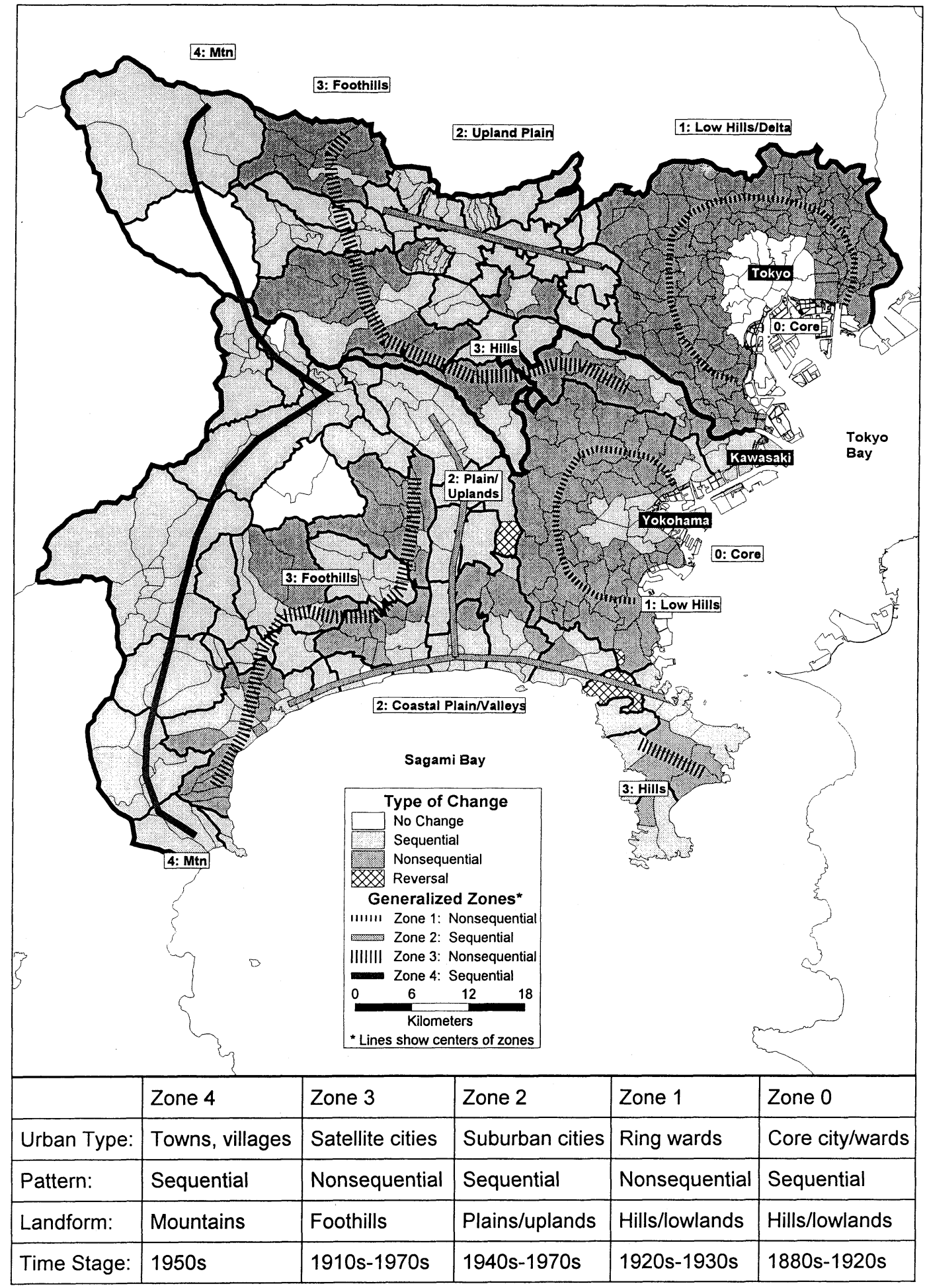

Figure 5. Urbanization transition zones in Tokyo and Kanagawa. 
immediate surroundings that were turned into an international port following the reopening of the country in the mid 1800s. This zone took its form in the late 1800 s through early 1910 s. Because this zone can be considered a subset of the now-expanded core cities, I have labeled it zone zero rather than zone one.

Zone 1: Each prefecture's core city directly annexed a broad band of surrounding towns and villages in the 1920s (for Yokohama) and 1930s (for Tokyo and Yokohama). In most cases, these towns and villages went directly into existing or new wards, thus skipping the ordinary-city level. By rechecking Figure 4, we can see that the inner portion of this external ring consists primarily of areas that had already become towns. The outer portion of the ring was still villages and thus skipped both town and city levels when annexed into wards. This zone took its form in the 1920s and 1930s.

Both zone zero and zone one occupy the area of low hills and valleys, as well as deltalands, in the eastern portions of the two prefectures.

Kawasaki city is somewhat of an anomaly, consisting of a major city that now has wards. It grew by expansion in the lowlands and hills along the Tama River, sandwiched between the core cities of Tokyo and Yokohama. It had both areas of sequential transition (the river lowlands) and nonsequential transition (the hills above the river on the south). Its expansion occurred in the 1920s and 1930s, the same time period for the rest of zone one.

Zone 2: This zone is complicated, requiring careful consideration of its location in relation to landforms and the expansion of the two core cities. It is a zone of suburban cities, almost all of which grew by sequential steps from village to town to city (including mergers and annexations).

In Tokyo prefecture, most of these current cities have essentially the same boundary as the village or town from which they arose, though a few have an early history of merger of many small villages into a single village, which later became a town and then a city. These suburban cities occupy the relatively flat Musashino upland plain west of the city of Tokyo itself. A few (Tachikawa and Musashino) became cities in the 1940s, but the greatest growth (from village to town and then to city) was in the 1950s through 1970s.

In Kanagawa, the situation is more complex. Here, a belt of cities started forming fairly early along Sagami Bay and on the Miura Peninsula. Growth of cities in the flatter inland areas of the Sagamino or Sagamihara uplands and the Sagami Plain occurred in the 1950s and onward, as it did in Tokyo's Musashino upland area. Most of these inland/coastal flatter areas had sequential growth from village to town to city. A key difference with the corresponding area of Tokyo prefecture is that most of Kanagawa's cities had considerable annexations of surrounding towns and villages (some sequential, some nonsequential).

Though some city formation occurred earlier, the decades from the 1940s through the 1970s can be considered the main growth period for zone two.

Zone 3: Though also complicated in shape, this zone is more easy to characterize than zone two. It consists of many large "foothill" cities. Some of them include large mountainous areas in addition to mountain valleys, foothills, and mountain-front lowlands. Others are primarily hills. Overall, most of these foothill cities had large areas of nonsequential transition, with a core town at the entrance to the mountains annexing many surrounding villages to become a city. Sometimes, the core town first became a small city, then annexed other areas. (These core areas are usually visible as light-gray areas within the 1995 city borders in Figure 4.)

Tokyo prefecture has four foothill cities: Ome, Akiruno (formerly Akikawa city and Itsukaichi town), and Hachioji along the mountains, and Machida in the Tama Hills, which separate the Musashino upland of Tokyo prefecture from the Sagamino upland of Kanagawa prefecture. Of these four cities, all but Akiruno have a nonsequential history of annexation of large areas of mountain villages. Akiruno grew more slowly than the rest, giving time for sequential expansion.

The foothill cities of Kanagawa prefecture include, from north-central to southwest, Atsugi, Isehara, Hiratsuka, Hadano, Minami-Ashigara, and Odawara. Of these, all but Isehara had primarily nonsequential transition histories for 
the city as a whole.

Two somewhat unique cases in Kanagawa are the major cities of Kawasaki and Yokosuka. These are both coastal cities rather than mountain-edge cities. Each contains core areas with sequential change, and outlying areas with nonsequential change. Kawasaki city's core area grew sequentially in the flat land along the Tama River, but it later directly annexed villages in the hills south of the river, thus creating a zone of nonsequential transition. Similarly, Yokosuka grew primarily sequentially in the low areas along the coast and nonsequentially into the hills of the Miura Peninsula. Both cities thus exhibited some of the characteristics of foothills cities, so I included them in zone three.

In general, the foothill cities of zone three are significantly larger in area than their suburban counterparts, especially in Tokyo prefecture. The time period of expansion of these cities is much broader than that of the suburban cities. Some of them first became cities early in the 1900 s, and many by mid-century. Also, several of them were already towns in the late 1800 s, long before most of the zone-two areas that became suburban cities. Thus, the cities of zone three can, in general terms, be thought of as satellite cities rather than suburban cities. Of course, with the infill of suburban cities in the upland plains between the core cities and the foothill cities, in most cases there is now no significant break in built-up area from core to suburban to satellite city.

Zone 4: The final zone consists of towns and a few remaining villages in the mountainous areas on the western edge of Tokyo prefecture and the northwestern, western, and southwestern edges of Kanagawa prefecture. With only two administrative levels in their history-first village, then town - these areas naturally have sequential transitions or no change at all. Most of them were consolidated in the 1950s by merging many villages or by annexation of the villages around a core town or towns.

\section{Conclusions}

The labels on the map and the table at the bottom of Figure 5 list the main properties of the different urbanization transition zones in Tokyo and Kanagawa prefectures. In summary, the zones can be characterized as follows:

Zone 0: Core city and ward areas of Tokyo and Yokohama, with sequential transitions (in the late 1800 s through 1910 s) or no change in administrative level. These core areas are located in the low hills and lowlands on the eastern sides of the prefectures abutting Tokyo Bay, where these urban settlements had their origins.

Zone 1: Ring wards of Tokyo and Yokohama, with nonsequential transitions in the 1920s and 1930 s as villages and towns were annexed directly into wards of the core cities. These areas are also in the low hills, valleys, and delta areas of the prefectures.

Zone 2: Suburban cities of Tokyo and Yokohama, with sequential transitions primarily in the 1940s through 1970s. These areas of villages, towns, and then cities are primarily on flatter land (upland plains, river valleys, or coastal plains) in the middle portions of the prefectures.

Zone 3: Foothill satellite cities, with nonsequential transitions. These cities were usually formed when a core settlement at the edge of the mountains annexed large expanses of surrounding villages. Kawasaki and Yokosuka are variants, as coastal cities that grew sequentially in flatter areas and nonsequentially into the surrounding hills. The time period of city formation is considerably wider in zone three, extending from the 1910 s through the 1970s. As the name implies, these cities are on the edge between the mountains and the plains, or on hills separating different flatland areas.

Zone 4: Mountain villages and towns, with sequential transitions. Changes in administrative level in these areas, from village to town, occurred primarily in the $1950 \mathrm{~s}$.

An interesting phenomenon is revealed: There is an alternating pattern of sequential and nonsequential transitions as one moves from zone to zone. Zone zero (the core cities and wards) had sequential transitions or no change, zone one (the ring wards) had nonsequential transitions, zone two (suburban cities) had sequential transitions, zone three (foothill satellite cities) had nonsequential transitions, and 
zone four (mountain villages/towns) had sequential transitions.

This alternating pattern is related to distance from the core areas of the cities of Tokyo and Yokohama. Immediately adjacent areas (the first zone) had nonsequential transitions, perhaps as one indicator of more-rapid urbanization of the core city by annexation of these surrounding areas into the core city itself. The second zone had sequential urbanization (with most cities being mid-sized, and with the change to city status occurring over more decades); these cities are adjacent to the core cities, and thus became inner suburbs. The third zone had nonsequential growth and resulted in quite-large cities as a core town or city on the mountain edge expanded by annexing many surrounding villages, sometimes simultaneously, sometimes sequentially; these cities have been more like satellite cities and, more recently, outer suburbs. Finally, the fourth zone had sequential transitions involving only one level change, from village to town.

The overall pattern could also be broken down into two super zones: (1) a "core city + expanded core city + suburban cities" zone in the heavily populated lowland areas, and (2) on a smaller urban scale but equal geographic scale, a "core foothills settlement+expanded foothills settlement + associated mountain towns/villages" zone in the mountain areas and edges.

In summary, this study has shown that there is variety in how individual administrative units have progressed along the continuum from village to town to city to ward in Tokyo and Kanagawa prefectures. Some areas followed a normal-direction sequential process, some a normal-direction nonsequential process, and a few even had a reversal in their history. These transition types have occurred in alternating zones of different types of urbanization, moving outward from the core cities of Tokyo and Yokohama on the east, through suburban cities in the middle uplands and plains, to satellite cities in the foothills of the western mountains, and then to a zone of mountain towns.

The sequence of changes in administrative level is only one of many possible measures of urbanization and factors in the formation of different zones within metropolitan areas. Other patterns to be considered include population distribution, built-up area, building density, economic activity, commuting, and daily interactions. Factors such as these may be considered as my GIS spatial history of greater Tokyo is expanded.

When the database is expanded to cover village $>$ town $>$ city $>$ ward sequences in the surrounding prefectures, it will be interesting to see what the spatial and temporal patterns of urbanization have been as the process extends northward into Saitama prefecture and eastward into Chiba prefecture, which have very different physical geographic and historical relationships to Tokyo.

\section{Acknowledgments}

This paper is an expansion of one component of the "GIS spatial history of Tokyo" that I created for my $\mathrm{PhD}$ dissertation in Urban Design and Planning at the University of Washington in 1997. The dissertation was partially funded by a one-year Hall Ammerer WRF Interdisciplinary Dissertation Research Fellowship. Acquisition of additional historical maps and other data sources in 1998 was partially funded by a University of Akron Faculty Summer Research Fellowship. I wish to thank Mr. Yota Kumaki of the Geographical Survey Institute of Japan for his assistance in obtaining reproductions of the historical topographic maps that underlie the village, town, city, and ward maps produced here. I have made every effort to make this analysis accurate and complete, based on a wide variety of records. However, there may still be errors of omission or commission. I would be pleased to be informed of any corrections by anyone who can provide suitable historical documentation.

(Received Nov. 21, 1999) (Accepted Aug. 25, 2000)

\section{References}

Bureau of Statistics. 1903-1995. Population censuses of Japan. Tokyo: Bureau of Statistics, Office of the Prime Minister.

Flüchter, W. 1980. Central place preference by social geographic groups with reference to the tributary area of Shibuya, southwest Tokyo. GeoJournal 4.3: 247-257.

Ishizuka, H., and Ishida, Y. 1988. Tokyo, the metropolis of Japan and its urban development. In Tokyo: Urban growth and planning, 1868-1988, 3- 
35. Tokyo: Center for Urban Studies, Tokyo Metropolitan University.

Kokudo Chiri-in. 1900s-1990s. $1: 200,000$ and 1: 50,000 topographic maps of Kanto area produced by Geographical Survey Institute of Japan. (J)

Masai, Y., ed. 1986. Atorasu Tokyo: Chizu de yomu Edo Tokyo/Atlas Tokyo: Edo/Tokyo through maps. Tokyo: Heibonsha. (JE)

Nakabayashi, I. 1980. Postwar growth of Tokyo and the architectonic change of its built-up area. $G e-$ ographical Reports, Tokyo Metropolitan University, 14/15, 111-139.

Nihon Chizu Center. 1992. Chizu de miru Tokyo no hensen. Tokyo: Nihon Chizu Center. (J)

Nihon Chizu Center. 1993. Chizu de miru Tama no hensen. Tokyo: Nihon Chizu Center. (J)

Nihon Chizu Center. 1996. Chizu de miru Yokohama no hensen. Tokyo: Nihon Chizu Center. (J)

Ota, T., ed. 1995. Bakumatsu iko shi-cho-son mei hensen keitozu soran. Tokyo: Toyoshorin. $(\mathrm{J})$

Reischauer, E. O., and Jansen, M. B. 1995. The Japanese today: Change and continuity. Enlarged edition. Cambridge, MA: Belknap Press of Harvard University Press.

Research Publications. 1973. International population census of Asia: Japan [microfilm]. Woodbridge, CT: Research Publications.

Seikosha, ed. 1998. Zenkoku chimei yomigana jiten: zenkoku shichoson no machi, cho, aza no soshuroku, 6 ed. Osaka: Seikosha. (J)

Shogakukan. 1996. Nihon chimei dai-jiten: rando japonica. Tokyo: Shogakukan. (J)

Siebert, L. 1997. Creating a GIS spatial history of Tokyo. PhD dissertation. Seattle: Department of Urban Design and Planning, University of Washington.

Takeuchi, R., and Kadokawa Nihon Chimei Dai-Jiten Hensan Iinkai, eds. 1978. Kadokawa nihon chimei dai-jiten, Volumes 11-14 (Saitama, Chiba, Tokyo, Kanagawa). Tokyo: Kadokawa Shoten. (J)

TMG Planning Bureau. 1989. Tokyo no toshi-keikaku hyakunenshi. Tokyo: Planning Bureau, Tokyo Metropolitan Government. (J)

Ueno, K. 1985. The residential structure of Tokyo in the 1910s (the Taisho era). Geographical Review of Japan 58B: 24-48.

Watanabe, S. 1984. Metropolitanism as a way of life: The case of Tokyo, 1868-1930. In Metropolis 18901940, ed. A. Sutcliffe, 403-429. London: Mansell Publishing.

Yokohama-shi Kikaku Chosei Kyoku. 1981. Minatomachi Yokohama no toshi keisei-shi (Development process of port city Yokohama). Yokohama: Yokohama-shi Kikaku Chosei Kyoku. (J)

Yoshida, T. 1937-1940. Dai nihon chimei jisho. Tokyo: Fuzanbo. (J)

Zheng, Xiao-Ping. 1991. Metropolitan spatial structure and its determinants: a case-study of Tokyo. Urban Studies, 28(1): 87-104.

$(\mathrm{J})$ : written in Japanese

(JE): written in Japanese with English abstract 